\title{
Correlation between Concrete Compressive Strength and Rebound Number of River Bed and Crusher Run Coarse Aggregate in Pokhara Valley
}

\author{
Er. Tek Bahadur Katuwal \\ Department of Civil and Geomatics Engineering \\ Tribhuvan University, Institute of Engineering, Pashchimanchal Campus, Nepal \\ E-mail: tekkatuwal184@gmail.com
}

\begin{abstract}
Concrete is principally composed of the mixture of cement, fine and coarse aggregates, and water and widely used for every building structure and other infrastructure. Aggregate has important functions as concrete making materials for the hardness and strength of concrete. The objective of this research was co - relation of compressive strength of concrete with Rebound number of crusher and river bed coarse aggregate in respect to the M20 grade of concrete with nominal mix. For this research, sample were taken from Hemja Crusher (HC), Hemja River Bed (HR), Kotre Crusher (KC), Kotre River Bed (KR) and considering sand from single source and commercially available single brand OPC cement. Fifteen cubes $(150 \mathrm{~mm} \times 150 \mathrm{~mm} \times 150 \mathrm{~mm})$ were cast for each sampled sources and the Compressive strength and Rebound number was determined after 7 days, 14 days and 28 days of curing.

In this research, statistical analysis was carried out to determine the best fit curve by using IBM SPSS. Finally the outcomes of this research indicated that the relationship between rebound number and compressive strength curve is liner.
\end{abstract}

Key words: Aggregate, Compressive Strength, Concrete, Rebound Number

\section{Introductions}

Concrete is a fundamental construction material used in building construction and other infrastructures. Concrete is principally composed of the mixture of cement, fine and coarse aggregates, and water. The constituents of concrete are cement, water, aggregates (fine and coarse aggregates), aggregates take about three-quarter of the volume of concrete with the coarse aggregates taking between 50 and
$60 \%$ of the concrete mix depending on the mix proportion used (1). The research work revealed that the aggregates are assumed to be of inert characteristics. The larger percentage of coarse aggregate in concrete mix makes it to contribute a lot to the strength of concrete. Its properties like shape, size, density, soundness, hardness, specific gravity and toughness also affect the strength of concrete.

Compressive strength of materials is usually 
determined by subjecting direct compressive load them to tests by destroying the testing samples. Such tests are the direct ways of determining strength of materials but require various heavy and expensive equipment or machines.

Schmidt rebound hammer is a non - destructive test of concrete, which measures the surface hardness of the hardened concrete. Rebound numbers affected by position of hammer, smoothness of test surface, type and size of aggregate used in the concrete. Rebound numbers also sensitive to local variations in the concrete, the presence of a large size of aggregate immediately underneath the plunger would result in an abnormally high rebound number and the presence of a void in a similar position would lead to a low rebound number value. The energy absorbed by the concrete was related both to its stiffness and strength, so that it was the combination of strength and stiffness that directs the rebound number. Because the stiffness of concrete is influenced by the type of aggregate used, the rebound number is not individually interrelated to the strength of concrete (2).

NDT method do not damage or affect the structural performance of components of the existing structures. They offers simplicity and rapidity in use to obtain the test result with economically on site. In addition, less expensive testing equipment are applied and almost all type of structures are possible to test the compressive strength. This also minimize the consumption of labour and preparatory work. (3)
For laboratory specimens or in - situ concrete test rebound hammer can easily use to determine the compressive strength of concrete. With defined energy rebound hammer hits the specimen and correlate with graph, finally calculate the compressive strength of the specimen. Rebound number value depends on the hardness of concrete, exposed surface of the specimen and efficiency of the testing machine. In the laboratory, most researchers apply rebound hammer to test standard cubes or cylinders and establish a good relation between compressive strength and rebound number for concrete. Non - destructive testing (NDT) methods are powerful tools for the structural assessment of existing concrete structures during maintenance or before repair $(4,5)$

It has been found, that the relation between the compressive strength and rebound number was directly proportional. It was concluded that the linear regression model gives the best fit curve with 95\% significance level to establish the relation between compressive strength and rebound number with different grade of concrete (6).

\section{Materials and Methods}

\subsection{Materials}

\subsubsection{Fine and coarse aggregates}

For this research, sampled coarse aggregate ( $25 \mathrm{~mm}$ down) were taken from Kotre Crusher, Kotre River Bed, Hemja Crusher and Hemja River Bed with considering sand from single source available in the Pokhara valley of Gandaki province. 


\subsubsection{Cement}

For this research, commercially available Single brands Ordinary Portland cement with Portable water free from any noticeable impurities was used.

\subsection{Methods}

\subsubsection{Batching of materials and Workability}

The batching of materials for concrete production was for $M_{20}$ grade with nominal mix. Fifteen similar concrete cubes $(150 \mathrm{~mm}$ $\mathrm{x} 150 \mathrm{~mm} \times 150 \mathrm{~mm}$ ) were prepared for each sampled source. The casting was made by filling each mould with freshly mixed concrete in three layers. Each layer was compacted manually using a $25 \mathrm{~mm}$ diameter steel tamping rod to give 25 strokes on a layer. The cube moulds were stored for 24 hours at room temperature. Apart from the variation in the Coarse aggregate sources the concreting procedures and water/ cement ratio were kept constant for all the samples.

\subsubsection{Compressive Strength tests}

Further the cube was removed from the mould and put into the fresh water in fully submerged condition. At the end of the 7 days, 14 days and 28 days of casting five cube samples were taken out for each sampled source. The excess water was allowed to drain off. The cube or cylinder was placed at the compression testing machine and load was applied gradually and uniformly till the failure occurs. Note down the maximum crushing load. Mean and characteristic compressive strength was calculated for all sets of results with $95 \%$ confidence level.
Compressive strength $(\mathrm{N} / \mathrm{mm} 2)=$ Maximum crushing load / Cross - sectional area of specimen.

\subsubsection{Schmidt Rebound Hammer Test}

Schmidt Rebound Hammer test is a nondestructive test. This is most suitable and widely used method for obtaining the correlation between the rebound number and compressive strength of concrete by compression machine simultaneously.

The concrete cube specimens were taken out from the curing tank and allowed to drain off the excess water from the cube specimen keeping it at room temperature for about 24 hours. Ten readings were taken on each of the two vertical faces using rebound hammers, the same face was later allowed to be tested in a compression testing machine. The plunger of rebound hammer on the specimen was kept vertically and the point of the impacts are $2 \mathrm{~cm}$ each other and the reading of rebound number was noted. Only the vertical faces of the cubes as casted were tested. A correlation between rebound numbers and strength of cube was then obtained.

\section{Results and Discussion}

\subsection{Compressive strength Results}

Table 1: Compressive Strength of M20 Grade of Concrete Cube

\begin{tabular}{|l|l|l|l|}
\hline \multirow{2}{*}{ Source } & \multicolumn{3}{l|}{ Compressive strength (Mpa) } \\
\cline { 2 - 4 } & Seven Days & Fourteen Days & Twenty Eight Days \\
\hline KC & 18.63 & 23.89 & 28.62 \\
\hline KR & 16.16 & 19.89 & 24.41 \\
\hline HC & 17.3 & 21.53 & 25.94 \\
\hline HR & 13.93 & 18.67 & 24 \\
\hline
\end{tabular}


In the laboratory, experimental results of M20 grade of concrete cube with different sources of aggregate are given in Table 1.

\subsection{Average Rebound Number of Sampled} Cube

Table 2: Average Rebound Number of M20 Grade of Concrete Cube

\begin{tabular}{|c|c|c|c|}
\hline Days & Seven & Fourteen & Twenty Eight \\
\hline Source & Rav & Rav & Rav \\
\hline KC & 22.3 & 26.8 & 32.6 \\
\hline KR & 20.2 & 23 & 29.6 \\
\hline HC & 21 & 24.2 & 30.1 \\
\hline HR & 18 & 22.8 & 28.8 \\
\hline
\end{tabular}

By using the Schmidt Hammer, the sampled sources were tested and experimental results are given in table 2 .

\subsection{Statistical Analysis}

Table 3: Curve Estimation Model of Rebound

Number and compressive Strength KC

\begin{tabular}{|c|c|c|c|c|c|}
\hline & \multicolumn{5}{|c|}{ Model Summary } \\
\hline Model & $\mathrm{R}$ & $\begin{array}{c}\mathrm{R} \\
\text { Square } \\
\end{array}$ & Adjusted R Square & $\begin{array}{c}\text { Std. Error of the } \\
\text { Estimate }\end{array}$ & \\
\hline Linear & 0.999 & 0.998 & 0.995 & 0.346 & \\
\hline Logarithmic & 0.995 & 0.989 & 0.979 & 0.729 & \\
\hline Power & 0.994 & 0.988 & 0.976 & 0.033 & \\
\hline \multirow[t]{2}{*}{ Exponential } & 0.987 & 0.973 & 0.947 & 0.05 & \\
\hline & \multicolumn{5}{|c|}{ ANOVA } \\
\hline \multirow{2}{*}{ Model } & Sum of & \multirow{2}{*}{ df } & \multirow{2}{*}{ Mean Square } & \multirow{2}{*}{$\mathrm{F}$} & \multirow{2}{*}{ Sig. } \\
\hline & Squares & & & & \\
\hline Linear & 49.827 & 1 & 49.827 & 415.681 & 0.03 \\
\hline Logarithmic & 49.415 & 1 & 49.415 & 92.935 & 0.07 \\
\hline Power & 0.092 & 1 & 0.092 & 82.533 & 0.07 \\
\hline \multirow[t]{2}{*}{ Exponential } & 0.09 & 1 & 0.09 & 36.522 & 0.1 \\
\hline & \multicolumn{5}{|c|}{ Coefficients } \\
\hline \multirow{2}{*}{ Model } & \multicolumn{2}{|c|}{$\begin{array}{c}\text { Unstandardized } \\
\text { Coefficients }\end{array}$} & $\begin{array}{l}\text { Standardized } \\
\text { Coefficients }\end{array}$ & \multirow{2}{*}{$\mathrm{t}$} & \multirow{2}{*}{ Sig. } \\
\hline & B & $\begin{array}{c}\text { Std. } \\
\text { Error }\end{array}$ & Beta & & \\
\hline Linear & 26.285 & 1.289 & 0.999 & 20.388 & 0.03 \\
\hline Logarithmic & 0.963 & 0.1 & 0.995 & 9.64 & 0.07 \\
\hline Power & 1.128 & 0.124 & 0.994 & 9.085 & 0.07 \\
\hline Exponential & 0.041 & 0.007 & 0.987 & 6.043 & 0.1 \\
\hline
\end{tabular}

The model was used to develop the relationship between the compressive strength and rebound number of concrete using IBM SPSS considering 4 types possible alternative models as linear, logarithmic, power and exponential analysis part covered in Table 3. The value of $\mathrm{R}$ - square, $\mathrm{F}$ - significance and $t$ - significance of linear model is precise and reliable than other model. So linear modal hold good fit curve line for correlation analysis of rebound number and compressive strength of concrete.

\subsection{Relation between compressive strength of concrete and Rebound number:}

Linear modal hold good fit curve line for correlation analysis of rebound number and compressive strength of concrete. This linear relation between rebound number and compressive strength is illustrate in given figure.

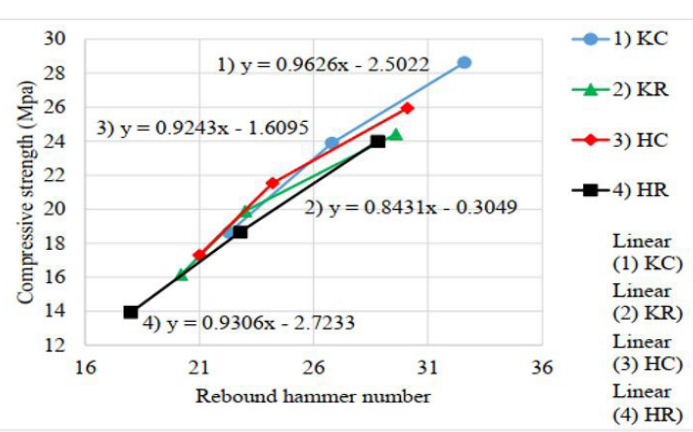

Figure 1 : Relation between compressive strength of concrete and Rebound number

The following linear equations have been proposed for M20 grade of concrete with different sources of crusher and river bed coarse aggregate in case of Pokhara valley.

$f_{c m}{ }^{\prime}=0.9626 * \operatorname{Rav}-2.5022 \quad$ (1) equation for KC Source 
$f_{c m}{ }^{\prime}=0.8431 * \mathrm{Rav}-0.3049(2)$

equation

for KR Source

$f_{c m}{ }^{\prime} \quad=0.9243 * \operatorname{Rav}-1.6095$ (3) equation

for HC Source

$f_{c m}{ }^{\prime} \quad=0.9306 * \operatorname{Rav}-2.7233$ (4) equation

for HR Source

\begin{tabular}{|c|c|c|c|c|c|c|c|c|c|c|c|c|}
\hline Days & \multicolumn{4}{|c|}{ Seven } & \multicolumn{4}{|c|}{ Fourteen } & \multicolumn{4}{|c|}{ Twenty Eight } \\
\hline Source & Rav & $\mathrm{fcm}$ & $\mathrm{fcm}^{\prime}$ & $\%$ error & Rav & $\mathrm{fcm}$ & $\mathrm{fcm}^{\prime}$ & $\%$ error & Rav & $\mathrm{fcm}$ & $\mathrm{fcm}^{\prime}$ & $\%$ erro \\
\hline $\mathrm{KC}$ & 22.3 & 18.63 & 18.96 & 1.76 & 26.8 & 23.89 & 23.30 & -2.55 & 32.6 & 28.62 & 28.88 & $\begin{array}{l}0.90 \\
\end{array}$ \\
\hline KR & 20.2 & 16.16 & 16.73 & 3.38 & 23 & 19.89 & 19.09 & -4.21 & 29.6 & 24.41 & 24.65 & 0.98 \\
\hline $\mathrm{HC}$ & 21 & 17.3 & 17.80 & 2.81 & 24.2 & 21.53 & 20.76 & -3.72 & 30.1 & 25.94 & 26.21 & 1.04 \\
\hline HR & 18 & 13.93 & 14.03 & 0.70 & 22.8 & 18.67 & 18.49 & -0.95 & 28.8 & 24 & 24.08 & 0.32 \\
\hline
\end{tabular}

Where, $\mathrm{fcm}^{\prime}$ is forecasted compressive strength (in Mpa) and Rav is measured average rebound number on the same grade of concrete. The error percentage between the forecasted and experimental results of compressive strength for $\mathrm{KC}, \mathrm{KR}, \mathrm{HC}$ and $\mathrm{HR}$ are within $\pm 2.55 \%, \pm$ $4.21 \%, \pm 3.72 \%$ and $\pm 0.95 \%$ respectively are given in Table 4 . These percentage of error are in acceptable limit of error.

\section{Conclusions and Recommendations}

\subsection{Conclusions}

Best on the results of the investigation carried out and statistical analysis, relation between rebound number and compressive strength of concrete has been developed for sampled sources with linear regression model. It has been concluded that, with the help of these correlation equations Schmidt hammer strength evaluation techniques can be used for concrete made with similar material in the construction work for more reliable quality evaluation in case of Pokhara valley.

\subsection{Recommendations}

Based on the above conclusion, it is recommendations that the Schmidt hammer test can be carried out to determine the compressive strength of existing structure in Pokhara valley which are constructed by using the coarse aggregate from crusher or river bed.

\section{References}

[1] Waziri, B.S., Bukar, A.G., and Gaji, Y.Z.A., "Applicability of Quarry Sand as a Fine Aggregate in the Production of Medium Grade Concrete", Continental J. Engineering Science, Vol. 6, pp. 1-6, 2011.

[2] Neville, A.M., "Properties of Concrete", Fifth Edition, Longman Group Ltd. London, 1981.

[3] Kiviste, M., Miljan, J., "Structural Concrete Compressive Strength Determination with Rebound Hammer", LZUU mokslo darbai, Vol. 47, pp. 27, 2007.

[4] Bungey, J. H., Millard J. H., Grantham, M. G., "Testing of concrete structures", New York, Vol. pp. 352, 2006.

[5] ACI 2013, Nondestructive Test Methods for Evaluation of Concrete in Structures, ACI 282.2R - 13, Michigan American Concrete Institute.

[6] Sha, M.L., 2002, "Strength Evaluation Concrete based on variation of Sources of Aggregates", M.Sc. Thesis, Department of Civil Engineering, TU Pulchowk Campus, Nepal, 2002. 